\title{
REPRESENTAÇÃO DEMOCRÁTICA: AUTONOMIA E INTERESSE OU IDENTIDADE E ADVOCACY
}

\section{LUIS FELIPE MIGUEL}

Nas últimas décadas, o debate sobre a representação política tem focado as insuficiências dos modelos formalistas. Teóricas feministas recuperam o valor da representação descritiva, renomeada como "política de presença”, que justificam com base na noção de "perspectiva social", desenvolvida na obra de Iris Marion Young. Numa direção em grande medida oposta, Nadia Urbinati enfatiza o caráter de advocacy da representação, démarche que ganha grande influência, inclusive no Brasil. Contra tais propostas, afirmo a necessidade de uma teoria da representação que volte a dar centralidade à categoria do "interesse", mas que, simultaneamente, dê ênfase à demanda por autonomia dos representados.

Palavras-chave: representação política, interesses, perspectivas sociais, advocacy, autonomia.

Recebido: 15/08/2010 Aprovado: 05/09/2011

\section{DEMOCRATIC REPRESENTATION: AUTONOMY AND INTEREST OR IDENTITY AND ADVOCACY}

In the last decades, debates about political representation have focused the insufficiencies of formalist models. Feminist thinkers recover the value of descriptive representation, renamed as "politics of presence", that they justify based on the notion of "social perspective", developed by Iris Marion Young. In a direction which is, in a large extent, opposite, Nadia Urbinati emphasizes that representation has a character of advocacy, a turn with great influence, even in Brazil. Against such proposals, I maintain the necessity of a theory of representation that gives centrality to the category of "interest", but that simultaneously emphasizes the demand for autonomy by the represented.

Keywords: political representation, interests, social perspectives, advocacy, autonomy. 


\section{REPRESENTAÇÃO DEMOCRÁTICA: AUTONOMIA E INTERESSE OU IDENTIDADE E ADVOCACY*}

Luis Felipe Miguel

O debate sobre representação política cresceu enormemente em complexidade nas últimas décadas. Em 1967, quando publicou seu hoje clássico The concept of representation, que em grande medida assentou as bases da discussão, Hanna Pitkin podia desdenhar os modelos descritivos como ingênuos e afirmar a superioridade da representação "formalista”, baseada em autorização e accountability. De lá para cá, a ausência de similaridade entre representantes e representados ganhou a dimensão de um problema político de primeira grandeza, ao mesmo tempo em que decaíram as esperanças nos mecanismos de accountability eleitoral como

\footnotetext{
* A ideia deste artigo brotou de conversas com Assis Brandão. Muitos de seus pontos foram depois discutidos com Flávia Biroli. Raquel Boing Marinucci chamou minha atenção para o movimento da neurodiversidade. Regina Dalcastagnè leu e comentou uma versão preliminar. Agradeço a todos, bem como aos participantes dos espaços em que versões preliminares foram apresentadas e discutidas (I Simpósio Nacional de Ciências Sociais, em Goiânia, de 17 a 20 de novembro de 2009; V Congreso Latinoamericano de Ciencia Política, em Buenos Aires, de 28 a 31 de julho de 2010; e $7^{\circ}$. Encontro da Associação Brasileira de Ciência Política, no Recife, de 4 a 7 de agosto de 2010). Agradeço também ao CNPq, que apoia o projeto de que este artigo é fruto, com uma bolsa de Produtividade em Pesquisa e com recursos do edital n. 20/2010. Permaneço, é claro, único responsável pelos erros e omissões.
} 
promotores da responsividade política. Modelos que Pitkin julgava superados ressurgem, repaginados, como formas de remediar os problemas da democracia representativa.

Por um lado, essa mudança indica a crescente inconformidade com formas de exclusão política que as correntes liberais tendem a ignorar. As visões que defendem a "política de presença”, para usar a expressão de Anne Phillips (1995), ou formas alternativas de verbalização das preferências dos grupos subalternos tocaram em pontos sensíveis do ordenamento político liberal. Mas terminaram obscurecendo de tal modo elementos centrais do fenômeno que mesmo seu potencial crítico foi diluído. Assim, eu organizo o artigo em torno das relações entre representação, interesses e poder. Meu objetivo, ao discutir algumas teorias recentes da representação política, é pontuar a necessidade de recolocar a noção de interesse no centro da nossa compreensão da representação política, bem como de restabelecer o entendimento que a atividade 26 representativa é uma forma de exercício de poder.

Num texto provocativo, Ian Shapiro se contrapõe à teoria deliberativa e proclama a necessidade de voltar a uma compreensão realista da política: "Chega de deliberação, política é sobre interesses e poder" (Shapiro, 1999). Este artigo participa dessa mesma percepção. Não se trata de uma coincidência. $\mathrm{O}$ alvo de Shapiro, a virada deliberacionista do pensamento político crítico, a partir dos anos 1980, é o pano de fundo das démarches na teoria da representação com as quais dialogo. Há um esvaziamento do caráter conflitivo da política, ao mesmo tempo em que a posição crítica deixa de remeter a valores substantivos, invocando, em seu lugar, um ideal de justiça que é agnóstico em relação às diversas concepções de bem e basicamente procedimental.

Não cabe, aqui, discutir as múltiplas vertentes do deliberacionismo - parte das quais, aliás, caminhou para uma acomodação quase completa com o liberalismo -, nem mesmo sua relação com as vertentes da teoria da representa- 
ção que pretendo enfocar (Faria, 2010; Mendonça, 2011). O que importa é observar que uma abordagem crítica do ordenamento das "democracias realmente existentes", preocupada com a igualdade política, não pode abrir mão de uma compreensão realista do funcionamento da política. E as fontes para tal compreensão, muito mais do que nas teorias alternativas hoje em voga, estão no pensamento liberal e em seu filho enjeitado, o marxismo.

Por realismo indico a tradição que remonta a Maquiavel, focada no entendimento de que os conflitos políticos possuem sua própria gramática. Em particular, essa tradição reconhece que os embates políticos não se resolvem em termos de justiça, ainda que mobilizem diferentes concepções de justiça e que sua capacidade de se vincular a tais tradições tenha impacto em sua efetividade. São embates por poder, formulação que não implica que os agentes políticos sejam necessariamente "maus", segundo a moralidade convencional, ou insensíveis às preocupações e ao bem-estar de outros. Indica apenas que o poder é o recurso necessário para a realização de qualquer objetivo político, até mesmo para a efetivação de alguma determinada concepção de justiça.

A política democrática - cujo "gesto inaugural", para usar a bela expressão de Claude Lefort, é "o reconhecimento da legitimidade do conflito" (Lefort e Gauchet, 1971, p. 8) - coloca a questão em outro patamar. Há uma norma de reciprocidade, portanto de justiça, quando se reconhece que são legítimas a presença, a discordância e a ação do outro em busca de suas próprias preferências. A construção da democracia tanto abraça quanto se contrapõe ao caráter agonístico da luta política. Tal tensão não pode ser eliminada, seja na prática, seja na reflexão teórica, pois a busca de uma democracia isenta do conflito político nega seu próprio caráter democrático.

Neste artigo, centro a discussão nas contribuições de Iris Marion Young e de Nadia Urbinati, levando em conta, 
é claro, que elas se movem em patamares bastante diferenciados. A representação política era um elemento, entre outros, no esforço teórico de Young, que ambicionava realizar uma ampla revisão crítica dos princípios do liberalismo, ao passo que Urbinati busca se firmar como uma teórica da representação.

Em relação a Young, tratarei sobretudo do conceito de "perspectiva social”, tal como apresentado em Inclusion and democracy, não fazendo mais do que referências laterais à sua obra mais importante, Justice and the politics of difference, que apresenta uma percepção bastante diferenciada da política (e na qual a representação ocupa posição bem menos central). A primeira seção do texto questiona o deslocamento que a noção de perspectiva acabou por promover no entendimento da representação, colocando os interesses em segundo plano, e como isso repercute na possibilidade de uma prática política emancipatória.

28 Quanto à segunda, vou privilegiar seu influente Urbinati (2000), deixando em segundo plano obras posteriores, como Urbinati (2006) e, sobretudo, Urbinati (2010), que apresentam transformações significativas em relação ao texto que elegi. Como argumento na segunda seção deste paper, a noção de "representação como advocacy" e ainda mais outras que lhe são próximas, como "representação virtual" (Gurza Lavalle, Houtzager e Castello, 2006) ou "representação por afinidade" (Avritzer, 2007), revalorizam os interesses, mas não levam em conta as relações de poder que se estabelecem entre representantes e representados, e não dão atenção à necessidade de ação autônoma destes últimos.

Na breve conclusão, vinculo representação, interesses e autonomia. O desafio da construção de uma representação democrática é permitir que indivíduos e grupos capazes de definir autonomamente seus interesses se vejam representados por agentes com os quais tenham identidade e capacidade de interlocução. Não tenho a pretensão de apresentar algum tipo de 
resposta para este desafio. Apenas aponto, por um lado, que soluções aparentemente fáceis não o resolvem e, por outro, que não é algo que se equacione com algum tipo de engenharia política, mas que depende de condições sociais mais propícias à participação política e ao exercício autônomo de direitos e competências. Dito de outra forma, o velho nó da conjugação entre democracia e desigualdade permanece sem ser desatado.

\section{Interesses e perspectivas}

Se fosse para fazer uma análise da concepção corrente da representação política, presente no senso comum, na mídia e no autodiscurso dos próprios agentes do campo político, ela provavelmente se cindiria em duas. De um lado, um requisito normativo de atenção ao "bem comum" ou algo similar, frouxamente definido a ponto de nele caberem tanto Burke quanto Rousseau. Do outro, a percepção de que as esferas representativas são a arena em que se resolvem os embates entre "grupos de interesse", entendidos de acordo com a vulgata pluralista que nasce da obra do primeiro Robert Dahl e de David Truman.

O conceito de "interesse" é central para a ciência social e também particularmente complexo ${ }^{1}$. Não pretendo, aqui, iniciar uma discussão exaustiva, mas identificar três problemas principais que precisam ser enfrentados. Em primeiro lugar, a relação entre interesse e egoísmo. A afirmação da centralidade do interesse é, muitas vezes, tomada como incluindo a postulação de um comportamento egoísta próprio a uma "natureza humana". Não se trata, porém, de afirmar a universalidade do autointeresse na agência humana,

\footnotetext{
1 Hirschman (1979 [1977]) faz uma erudita e fascinante reconstituição dos usos do "interesse" no pensamento europeu, desde seu surgimento como "interesse de Estado", sua expansão para abranger também os agentes privados e, enfim, o movimento pelo qual a "paixão dos bens e do dinheiro" perde seu caráter de "paixão" e torna-se o interesse por excelência, não apenas racional como capaz de moderar as outras paixões.
} 
flanco que é atacado por aqueles que buscam demonstrar a banalidade do altruísmo ${ }^{2}$. De fato, não é possível reduzir as ações humanas a uma única motivação e a ideia de um autointeresse onipresente só se sustenta caso o conceito se torne tautológico (minha ação revela meu autointeresse, portanto toda ação é autointeressada). O ponto é entender que, para além do comportamento específico deste ou daquele agente individual, a dinâmica do conflito social só é compreendida com referência aos interesses dos grupos que dele participam.

O segundo problema é a relação entre interesses, preferências e escolhas. Como observou Sunstein (1997, pp. 15-16), a corrente da rational choice tende a equiparar preferências e escolhas, como se cada escolha fosse o índice imediato de uma preferência que nela se desvela. No entanto, escolhas são fruto da interação de preferências com contextos e, por si sós, pouco dizem das motivações dos agentes. 30 Por exemplo: diante da opção entre A e B, eu escolho A, não porque prefira $\mathrm{A}$ - posso ser indiferente ou mesmo preferir B -, mas porque, no contexto em que minha decisão é tomada, a escolha de A projeta diante dos outros (ou de mim mesmo) uma determinada imagem. Assim, o que eu prefiro não é A nem B, mas essa imagem; e a escolha, em si

\footnotetext{
2 Elster (1990, p. 46) define o altruísmo puro como contribuição anônima (portanto não explicável pela busca de prestígio social) a beneficiários indeterminados (portanto não explicável pelo prazer de proporcionar prazer). Ainda que definido de forma tão estrita, o altruísmo motivaria transferências globais de cerca de $1 \%$ da renda das pessoas, um volume significativo. O conceito de altruísmo manejado por Elster, no entanto, é passível de críticas. Por um lado, é amplo em excesso, já que não leva em conta as motivações egoísticas vinculadas a crenças no sobrenatural (salvação da alma, vida eterna, reencarnação etc.). Por outro, é estreito, já que exige que a ação altruísta possua uma ou mais pessoas como beneficiárias, não aceitando que seja voltada ao bem de uma coletividade abstrata ("a nação", "o povo", "o partido" ou ainda "o planeta"). Seja como for, o sacrifício do próprio dinheiro, conforto e segurança em prol de outras pessoas, próximas ou distantes, ou de uma causa é algo corrente. Chamá-lo de "egoísta" por conta do envolvimento afetivo ou do sentimento de dever mobilizados exigiria que uma ação, para ser considerada genuinamente altruísta, fosse não motivada, o que é um evidente contrassenso.
} 
mesma, não revela minha preferência, a menos que outros elementos sejam acrescentados ao cenário.

É possível, então, entender preferência como a predileção por alguma situação ou estado, que leva ao interesse em determinadas medidas e a escolhas em situações concretas. Minha preferência por mais tempo livre me leva a ter interesse na redução da jornada de trabalho e, assim, a determinadas escolhas políticas. $\mathrm{O}$ interesse se estabelece como o móvel privilegiado do conflito político porque organiza as escolhas e porque as desavenças se ligam a medidas que podem ou não ser efetivadas, não a predileções abstratas.

A frequente opção por trabalhar com as "escolhas" se liga ao fato de que elas são identificadas sem ambiguidade, ao contrário do que acontece com interesses ou preferências - e esse é o terceiro problema. A tradição utilitarista que subjaz à boa parte da ciência política estabelece que cada um é o melhor juiz dos próprios interesses, ignorando os processos sociais de produção das preferências. Do outro lado, uma tradição marxista afirma que a "falsa consciência" impede que os integrantes dos grupos dominados identifiquem seus verdadeiros interesses, numa leitura mecânica e simplista do processo de formação das preferências. Ambas as posições são insatisfatórias. É necessário reconhecer tanto a possibilidade de manipulação quanto a ausência de um “interesse verdadeiro" objetivamente identificável, posição paradoxal, mas que leva em conta a autonomia diferenciada dos diversos sujeitos sociais na produção de suas próprias preferências e interesses (Sunstein, 1997, p. 5; Miguel, 2003, pp. 129-30). A privação material ou o "imperialismo cultural", isto é, a importação de chaves simbólicas para a leitura do mundo produzidas por outros grupos sociais (Young, 1990a, p. 58), são impedimentos importantes à formação autônoma de preferências.

As dificuldades com o conceito de interesse justificam a mudança patrocinada por Iris Marion Young, que apresenta 
opiniões e perspectivas como elementos paralelos a serem levados em conta na avaliação dos sistemas representativos. Uma perspectiva social se define como "o ponto de vista que membros de um grupo têm sobre processos sociais por causa de sua posição neles" (Young, 2000, p. 137). São duas as vantagens principais em relação aos interesses: as perspectivas indicam a sensibilidade da experiência gerada pela posição de grupo, sem postular um conteúdo unificado - são um ponto de partida, não de chegada, ao contrário dos interesses. E as perspectivas não podem ser representadas por outros, uma vez que sensibilidade e experiência não se transferem. Elas servem, assim, de justificativa para uma política de presença.

Em outra ocasião, tratei dos problemas associados ao conceito de perspectiva, tal como apresentado por Young (Miguel, 2010). Não fica claro, na obra dela, se a perspectiva se associa à dominação social - isto é, se trabalhadores e patrões, mulheres e homens ou negros e brancos pos32 suem perspectivas diferenciadas por efeito das estruturas de uma sociedade classista, machista e racista - ou é um atributo do "ser-no-mundo". Também não é clara a relação que se estabelece entre vivência e pensamento. Young se distancia ostensivamente de duas correntes que explicitam essa relação: o chamado "pensamento maternal", que postula que a responsabilidade feminina pelo cuidado com os filhos engendra uma moralidade diferenciada (Ruddick, 1989; Elshtain, 1993 [1981]; Hartsock, 1998 [1983]), e o entendimento marxista de ideologia como efeito do processo de vida ${ }^{3}$. Mas não desenvolve sua própria explicação de como experiências similares produzem perspectivas similares, exceto por breves e insatisfatórias remissões à fenomenologia de Merleau-Ponty, em seus escritos sobre corpo (Young, 1990b).

\footnotetext{
3 "A consciência não pode jamais ser outra coisa que o ser consciente, e o ser dos homens é o seu processo de vida real. [...] Não é a consciência que determina a vida, mas a vida que determina a consciência” (Marx e Engels, 2007 [1846], p. 94).
} 
Aqui, vou me restringir a duas questões que interessam mais de perto à discussão. Ao enfatizar que a perspectiva é um ponto de vista sobre o mundo, que não se desdobra necessariamente em interesses, abre-se espaço para uma leitura epistêmica da pluralidade de vozes nos locais de tomada de decisão. A presença dos grupos subalternos deixa de ser um imperativo de justiça, vinculado à necessidade de evitar a concentração de recursos de poder político em uns poucos, para se tornar um mecanismo de melhoria da qualidade da deliberação.

Essa percepção se torna visível, na obra de Young, à medida que ela se aproxima de uma abordagem deliberacionista da política. O esforço para admitir no debate outras contribuições além do argumento racional, que ela partilha com outros teóricos deliberativos preocupados com os padrões de exclusão social (Young, 2000, pp. 52-80; Dryzek, 2000), vincula-se à ideia de que a multiplicidade de pontos de vista ampliará a compreensão da realidade. Na ausência de um ponto de vista do universal, que para Young (1990a) é apenas a imposição da perspectiva dominante, precisamos de todo o mosaico de perspectivas parciais a fim de entendermos a complexidade do mundo social.

As perspectivas divergem, mas também se complementam, e o reconhecimento mútuo entre elas pode produzir, senão o consenso, ao menos a convivência respeitosa e a superação da unilateralidade cega. $\mathrm{O}$ "conhecimento situado" das diferentes posições de grupo é um recurso "para alargar o entendimento de todos e movê-los para além de seus próprios interesses paroquiais" (Young, 2000, p. 109). Por mais que explique que o "julgamento objetivo" que defende, pelo qual meu próprio interesse é apenas um entre outros, não é uma forma de transcendência das particularidades (Young, 2000, p. 113), ressurge aqui um ideal de imparcialidade, transmutado na absorção das perspecti- 
vas alheias (Squires, 2001, p. 20) ${ }^{4}$. Assim, o conflito, que se associa aos interesses, é sobrepujado pela diversidade, que é própria das perspectivas.

Nos momentos em que reintroduz o conflito em seu pensamento, Young (2001) também se afasta da teoria deliberativa. A questão passa a ser o enfrentamento de padrões concretos de dominação e opressão, não o reconhecimento empático do outro. E os interesses em oposição ganham preeminência no entendimento dos embates políticos. Não foi essa faceta da sua obra, porém, que teve impacto nos estudos sobre representação.

Uma formulação radical da compreensão epistêmica da política de presença está na obra de Robert Goodin. Para ele, a boa prática deliberativa exige o diálogo interno com vozes que representariam os outros, uma vez que o diálogo concreto é inviável na prática. É fundamental a empatia, para que cada um possa reproduzir, em sua mente, as posições que, 34 supõe-se, seriam as defendidas pelos outros (Goodin, 2000). Este acaba por ser o mecanismo de inclusão por excelência. Observando a impossibilidade da presença de representantes de todos os grupos subalternos, dada a multiplicidade de clivagens sociais potencialmente relevantes, Goodin propõe que alguns desses grupos estejam representados. O objetivo é "representar o fato irredutível da diversidade [sheer fact of diversity], mais que o exato parâmetro desta diversidade" (Goodin, 2004, p. 463), lembrando a todos os outros ausentes e acionando os mecanismos mentais de empatia que garantiriam a boa representação.

Assim, a visão epistêmica se aproxima de uma percepção idealista da política, em que a multiplicidade de vozes

\footnotetext{
${ }^{4}$ Squires apresenta uma "solução" para o dilema - utilizar uma noção menos exigente de imparcialidade, que não estabeleça um ponto de vista universal, mas apenas "inclusividade e ausência de viés" (Squires, 2001, p. 23). Creio que é uma solução meramente verbal, na medida em que não é possível determinar a ausência de viés fora de um ponto de vista universal.
} 
geraria uma visão mais completa da realidade e, assim, uma decisão cognitivamente superior. $\mathrm{O}$ conflito político fica afastado, o que é mais um efeito da influência da "democracia deliberativa". Conflito é, no final das contas, conflito de interesses e a defesa da política de presença tem a ver com a necessidade de que os múltiplos interesses se produzam e se manifestem na arena política. Considero um retrocesso o fato de que, na voga da "democracia deliberativa", as concepções críticas sobre a esfera política tenham paulatinamente desinflado o caráter conflitivo da política.

Dizendo de outra forma, uma noção útil de perspectiva não passa ao largo da relação entre as perspectivas e os interesses. Perspectivas sociais compartilhadas são a base a partir da qual interesses coletivos podem ser construídos. Numa sociedade desigual, os grupos dominados não possuem apenas perspectivas diferentes de grupos dominantes: possuem também interesses conflitantes. A perda de centralidade dos conceitos de dominação e opressão na obra de Young posterior a Justice and the politics of difference fez com que a ideia de perspectiva social se distanciasse das injustiças sociais. Com isso, a variedade de perspectivas se aproxima mais da pluralidade própria de uma sociedade multicultural e deixa desbotado o foco na estruturação das vivências de acordo com constrangimentos associados às desigualdades de poder, recursos materiais e prestígio social.

Mas não se trata somente de diversidade. A posição da mulher numa sociedade machista ou do negro numa sociedade racista não é apenas diferente da posição do homem ou do branco. É uma posição marcada pelos signos da subalternidade. Mulheres e negros possuem menos acesso às posições de poder, menos controle dos bens materiais. Estão mais sujeitos à violência e à humilhação. A ruptura com esse estatuto subalterno implica na revisão dos privilégios dos grupos dominantes. Ainda que muitos homens e muitos brancos possam ser solidários às reivindicações de mulheres e negros, há, 
sim, um conflito entre a emancipação de uns e a permanência do papel social dominante de outros.

Não é um "conflito de perspectivas", mas um conflito de interesses. Os grupos dominados, assim, precisam mais do que de um lugar para a verbalização de suas perspectivas. Precisam de espaços que lhes permitam constituir autonomamente seus interesses - o que foi chamado de "contrapúblicos subalternos" por Fraser (1992) - antes de colocá-los à prova nas arenas discursivas gerais. A ênfase exclusiva na pluralidade de perspectivas, obscurecendo o papel dos interesses, conta apenas metade da história e deixa de lado o elemento conflitivo que é inerente à política.

A noção de perspectiva, desvinculada de conflito, de interesses e de poder, permite tais desdobramentos. Além disso - e chego agora ao segundo problema que julgo importante abordar -, a presença de integrantes de grupos subalternos nos espaços decisórios não garante automaticamente uma 36 efetiva pluralidade de perspectivas. É necessário levar em consideração a influência homogeneizadora do campo político.

Um "campo", no sentido dado ao termo pela sociologia de Pierre Bourdieu, é um espaço social estruturado e estruturante das práticas daqueles que nele ingressam e nele desejam progredir. A adesão aos seus códigos é exigida, promovendo a reprodução de formas de exclusão. O campo político busca "enquadrar" as vozes diferentes, forçando adaptações e reduzindo o potencial disruptivo da incorporação de vozes dissonantes. Os grupos subordinados se veem diante de uma escolha entre "autenticidade" e "efetividade". Seu discurso e seu comportamento tornam-se mais eficazes quando se adaptam às regras do jogo estabelecidas, mas com isso a "diferença" que se queria representar é dissipada.

Há, portanto, um efeito reprodutor próprio do campo, que gera homogeneização, conformidade a normas, a expectativas, a padrões discursivos, e, nesse mesmo processo, perpetua a divisão entre sujeitos políticos ativos - os pro- 
fissionais, aqueles que dominam os códigos do campo - e a massa de "profanos", no sentido de Bourdieu, limitados a optar entre as ofertas que lhe são apresentadas. Isso põe em xeque o potencial emancipador que a incorporação de múltiplas perspectivas ao debate político promete.

Em suma, o campo político reproduz assimetrias e exclusões. A presença dos integrantes de grupos dominados nos espaços de poder não elimina, nem reduz substantivamente, por si só, a desigualdade política - apenas torna o conjunto de tomadores de decisão mais similar ao corpo social. Ela pode, sim, gerar tensões e ampliar os custos da reprodução da dominação, mas sempre na contramão dos mecanismos de exclusão e cooptação que o campo põe em funcionamento.

A homogeneidade do grupo politicamente dominante é mantida por uma série de barreiras com ação conjunta. A demanda por presença política contrapõe-se aos efeitos desses constrangimentos. Mas as estruturas do campo político resistem à inclusão efetiva, mantendo os representantes de grupos subalternos em posição periférica e impondo ônus simbólicos especiais à sua ação. A verbalização de suas perspectivas é distorcida pela necessidade de adaptação aos padrões que conferem legitimidade aos agentes políticos (um ponto ao qual voltarei na próxima seção).

O conceito de perspectiva mostra-se, então, uma má aposta para justificar a presença política de grupos subalternos. Uma via mais atraente coloca tal presença como uma questão de justiça. A demanda por presença política se justifica porque a posse do capital político, assim como do capital econômico, do capital cultural etc., engendra a possibilidade do exercício de poder - e a concentração do poder nas mãos de poucos é uma forma de injustiça social (daí a necessidade de redistribuição desses capitais). Assim como a associação entre uma maior ou menor possibilidade de aceder a tais formas de poder e determinadas caracterís- 
ticas imputadas, isto é, a monopolização dessas posições por uns poucos grupos, é também uma injustiça ${ }^{5}$.

As perspectivas, por sua vez, se mostram ferramentas úteis para pensar a produção social dos interesses. As vivências associadas a determinadas posições na sociedade geram pontos de vista que estão na raiz dos interesses sociais. $\mathrm{O}$ reconhecimento da importância das perspectivas produz a reivindicação de que tais grupos possuam espaços em que possam construir, de forma dialógica, um entendimento autônomo sobre seus próprios interesses. Mais do que diretamente na demanda por representação, está nesse ponto - que liga perspectivas compartilhadas e produção de interesses - o elemento mais produtivo do conceito de Young.

\section{Poder e autonomia}

A tensão entre autenticidade e efetividade, que foi descrita aqui como um efeito dos constrangimentos à ação dos 38 dominados impostos pela estrutura do campo político, aparece de forma diferente - neutra e mesmo positiva - na visão de Nadia Urbinati. A autora italiana se coloca como uma defensora das virtudes da representação política, um ponto constante em sua obra. A representação não é, para ela, um sucedâneo da participação ou mesmo da democracia direta, adotado faute de mieux. É uma forma superior de organização política, que deve ser avaliada por seus próprios méritos.

Urbinati indica duas vantagens principais da representação eleitoral. Ela

destaca a natureza idealizadora e julgadora da política [...], uma arte pela qual os indivíduos transcendem o imediatismo de sua experiência e de seus interesses [...].

\footnotetext{
${ }^{5}$ Não é necessário ir muito longe: tal monopólio fere a segunda parte do segundo princípio de justiça de Rawls.
} 
A representação - e o julgamento eleitoral que é parte necessária da representação democrática - projeta os cidadãos numa perspectiva orientada para o futuro e assim confere à política sua dimensão ideológica (Urbinati, 2000, p. 760; ênfases suprimidas).

O voto em candidato privilegiaria a longue durée, ao contrário do voto em questões, como na democracia direta, que refletiria demandas mais imediatas (Urbinati, 2006, p. 31).

A segunda vantagem, a mais relevante para a presente discussão, é que ela distancia os representantes de seus constituintes, o que tanto exige a produção de "formas de unificação [...] construídas simbólica ou politicamente" (Urbinati, 2006, p. 20; ênfases suprimidas $)^{6}$; quanto amplia o papel das ideias na política. Assim, a autora italiana se coloca nos antípodas da "política de presença". A autonomia dos representantes (não apenas no sentido do mandato livre burkeano, mas também da ausência de laços identitários) é necessária para o bom funcionamento dos processos deliberativos. $\mathrm{O}$ caráter democrático seria protegido pelo simples mecanismo eleitoral, encarnação do "poder negativo" dos cidadãos - a possibilidade de destituição dos governantes pela não recondução ao cargo (Urbinati, 2006, p. 29).

O poder negativo, tal como apresentado por Urbinati, não é uma mera reedição da "democracia protetora" dos utilitaristas (Macpherson, 1977 [1976]), em que a franquia eleitoral visa exclusivamente dar aos governados uma arma para evitar a tirania dos governantes. Os cidadãos possuem outros interesses além da não escravização e seu poder se exerce num julgamento eleitoral complexo e multifacetado.

Ao defender a ideia de representação como advocacy, Urbinati desenvolve com mais clareza a defesa do distanciamento entre o representante e seus representados. $\mathrm{O}$ advocate

${ }^{6}$ Ver também Urbinati (2006, p. 6). 
é definido como alguém que combina a vinculação "apaixonada" à causa de seus constituintes com a autonomia de julgamento (Urbinati, 2000, p. 773). De acordo com sua abordagem, essa solução é melhor tanto para os representados quanto para o funcionamento do sistema político geral. A noção de advocacy inclui compromisso com uma posição, mas não se confunde com o partidarismo cego. Os advocates são "defensores apaixonados e inteligentes" (Urbinati, 2000, p. 775), mas preparados para entender as razões alheias (Urbinati, 2000, p. 776). Assim, o conflito de interesses é admitido, mas controlado pelo distanciamento que os representantes são capazes de guardar em relação às posições que advogam. Esse distanciamento é o espaço para que a razão possa se fazer presente na arena política ${ }^{7}$.

Já para os representados, as vantagens se colocam em termos de eficácia. "Nós buscamos conseguir o melhor 40 defensor [de nossas posições], não uma cópia de nós mesmos" (Urbinati, 2000, p. 776). A expertise do profissional da política permite que os interesses sejam promovidos de maneira mais efetiva - uma versão repaginada do velho argumento da especialização funcional, contra o qual sempre se levantaram todos aqueles que viam a ação política como essencial para a liberdade, fossem republicanistas ou participacionistas. Na medida em que tal expertise se associa à posse de competências que são desigualmente distribuídas na sociedade, é provável que os advocates, não importa quais posições defendam, provenham dos mesmos grupos sociais. Mas isso não é um problema para Urbinati.

\footnotetext{
${ }^{7}$ Cumpre ressaltar que "Representation as advocacy" é o momento de maior aproximação de Urbinati com a teoria deliberativa. Na breve retomada, por vezes literal, que faz da noção de advocacy em seu Representative democracy (Urbinati, 2006, pp. 44-48), os elementos deliberacionistas já são deixados de lado. E no artigo "Unpolitical democracy" predomina um tom crítico em relação a pressupostos da corrente (Urbinati, 2010).
} 
Ainda que ela diga que a representação, tal como defende, é uma "política de presença por meio de ideias" (Urbinati, 2006, p. 247; ênfase suprimida), fica clara sua distância em relação às preocupações de autoras como Young ou Phillips. No máximo, Urbinati anota que "o representante que acredita na e partilha da visão de seus constituintes presumivelmente estará mais motivado e determinado a advogar sua causa" (Urbinati, 2006, p. 48). Mas não se trata de uma abertura para a importância das perspectivas sociais e sim de uma (tímida) desvinculação da ideia de que a representação é uma técnica a ser aplicada por um profissional que não liga para qual é sua clientela. A identificação é útil (embora, pelo que se depreende da prudente formulação de Urbinati, não obrigatória); a identidade, por outro lado, permanece supérflua.

Falta, na compreensão de Urbinati, a atenção a três elementos. Primeiro, o fato de que o representante ocupa uma posição de poder. Ele possui acesso a recursos políticos que o colocam em posição de autoridade em relação a seus próprios constituintes. Graças à especialização na política, possui também uma superioridade de conhecimento. A assimetria entre representantes e representados é um dos problemas da democracia representativa e o modelo de advocacy, com sua ênfase na eficácia, tende a agravá-la.

Também falta a Urbinati o entendimento das consequências geradas pelas assimetrias de recursos políticos entre representantes e representados. Sua aposta no "julgamento eleitoral”, que não é nada mais do que a crença no funcionamento dos mecanismos de accountability, é pouco sustentável. Esse julgamento é contaminado pela baixa informação dos eleitores, pelo baixo incentivo à capacitação política que a mera participação eleitoral provê e pelo distanciamento entre a vivência cotidiana e o mundo das decisões políticas. Um modelo que exige um fluxo de comunicação pujante e horizontal entre representantes e representados pode fun- 
cionar em seus próprios termos, mas não se aplica às sociedades desiguais realmente existentes ${ }^{8}$.

Por fim, falta a Urbinati entender que a representação política possui um caráter constitutivo, que não deve ser ignorado:

Se a sociedade é apreendida como estando composta de unidades elementares discerníveis, a representação consiste numa simples descrição, em uma tradução. Mas se a sociedade é considerada, ao contrário, como opaca e ilegível, a representação deverá tomar uma dimensão construtiva: para exprimir a sociedade, ela deve antes produzi-la (Rosanvallon, 1998, p. 119).

Reconhecer essa dimensão construtiva, que acompanha a ideia de representação política desde Hobbes, não significa que ela deva ser vista como arbitrária. A constru42 ção da sociedade ou, se preferirmos, da comunidade política deve respeitar elementos, tendências ou, para dizer o mínimo, um conjunto de possibilidades que é dado pelo próprio tecido social. Assim, mudanças nos padrões de pertencimento de grupo e processos de formação de identidades individuais e coletivas potencialmente geram desafios a formas antes estabelecidas e assentadas de representação/ construção das comunidades políticas.

Um dos principais desafios da representação política democrática reside aí: em não bloquear a constituição de determinadas identidades coletivas, nem impô-las autoritariamente, garantindo um diálogo entre representantes e representados que depende da capacitação política destes

\footnotetext{
${ }^{8}$ Num parágrafo da conclusão de Representative democracy, Urbinati observa a necessidade de controlar a influência do dinheiro e da mídia (Urbinati, 2006, pp. 236-237). É o único momento, em todo o livro, em que o mundo real aparece. Feito o lembrete, não se discute como tal controle pode ser efetivado, nem, na sua ausência, o que permanece de válido no modelo proposto.
} 
últimos. A delegação das funções representativas a advocates dotados de expertise superior pode gerar ganhos de eficácia, como quer Urbinati, mas apenas se as identidades e as preferências são percebidas como dados prévios. Como não o são, a delegação que a concepção de representação como advocacy prevê implica retirar dos constituintes a possibilidade de construir autonomamente suas preferências políticas - um incentivo, de fato, a que abracem "preferências adaptativas" (Knight e Johnson, 1997, p. 298), oferecidas por aqueles que, de uma posição social diferenciada, falam em seu nome.

A noção de representação como advocacy, tal como apresentada por Urbinati, deságua em interpretações menos cautelosas - no Brasil pelas mãos, por exemplo, de Avritzer (2007) e de Gurza Lavalle, Houtzager e Castello (2006). Os rótulos são variados: representação presuntiva, representação virtual, representação pelas organizações da sociedade civil, representação por afinidade. Sem querer aplainar as diferenças entre esses autores e essas concepções, há um ponto comum importante: é a ideia de que, cada vez mais, existem intermediários na relação entre Estado e sociedade civil (que são organismos da sociedade civil ou organizações não governamentais), aceitos como interlocutores legítimos, na condição de representantes de determinados interesses ou grupos. Como pretendo demonstrar, a despeito da riqueza de insights nelas contidos, tais interpretações aprofundam seriamente os problemas já identificados na posição de Urbinati, sobretudo porque retiram o último anteparo - o "julgamento eleitoral" - que garantia alguma esperança de controle dos representantes pelos representados. Tal como no caso de Young e Urbinati, minha discussão aqui ocorre com textos, não com autores - isto é, não farei mais do que referências breves a inflexões presentes em outras obras, quer de Avritzer, quer de Gurza Lavalle e seus colaboradores. 
Mesmo nos momentos em que se mostra mais receptiva à "representação democrática não eleitoral", Urbinati aponta os problemas da ausência de formas de autorização e accountability. Bem ou mal, a representação eleitoral garante um patamar de igualdade entre os representados, por meio do acesso de todos à franquia. "Não há igualdade equivalente de influência ou voz no domínio não eleitoral, onde as vantagens de educação, renda e outros recursos desigualmente distribuídos são mais capazes de se traduzir em padrões de sobre e sub-representação" (Urbinati e Warren, 2008, p. 405). Tal preocupação parece ausente em muitos estudos que tratam de advocates não eleitos.

"Representação política e organizações civis", de Gurza Lavalle, Houtzager e Castello, se apresenta como uma investigação empírica sobre organizações da sociedade civil em São Paulo, que os autores constatam que exercem funções representativas. Trata-se, então, de adaptar a teoria a uma 44 situação dada pela realidade. As entidades da sociedade civil "assumem compromissos de representação", num "esforço de intermediação orientado a conectar" os grupos sub-representados ao Estado e à política eleitoral (Gurza Lavalle, Houtzager e Castello, 2006, p. 44) ${ }^{9}$. A noção central, de "compromisso de representação", é retirada de Edmund Burke, que se torna assim inspirador da visão de representação virtual.

A referência a Burke é criticada por Avritzer, que observa que o autor irlandês defendia uma forma de representa-

\footnotetext{
9 Em texto posterior, tal capacidade de intermediação ganha uma nova dimensão, já que as organizações civis seriam promotoras da "accountability societal" (Gurza Lavalle e Castello, 2008). Não há espaço para desdobrar a discussão, mas o conceito de accountability societal, apresentado em primeiro lugar por Peruzzotti e Smulovitz (2002), parece-me provocar mais confusão do que esclarecimento. Na ausência tanto da obrigatoriedade de resposta por parte dos detentores do poder, quanto da possibilidade de aplicação de sanções por parte de seus supervisores, é difícil falar em accountability. A ideia de "mecanismos contrademocráticos", de Pierre Rosanvallon (nota 16, infra), mostra-se mais profícua.
} 
ção sem eleições, própria dos regimes monárquicos anteriores à Revolução Francesa. Assim, "na ânsia de legitimar uma forma de representação pós-eleitoral, Gurza Lavalle, Houtzager e Castello acabam resgatando um argumento pela legitimidade da representação pré-eleitoral" (Avritzer, 2007, p. 451). Creio que o problema é outro. A concepção burkeana - que passa, sim, pelo mecanismo eleitoral, como fica claro em sua expressão mais acabada, o "Discurso aos eleitores de Bristol" (1984 [1774] $)^{10}$ - incorpora a ideia de que o representante transcende os interesses de seus constituintes, seja por sua competência superior, seja por sua vinculação a um bem maior, o bem da nação, que ultrapassa as preferências mesquinhas dos simples eleitores. A superioridade do representante, por seu preparo ou por seus horizontes mais amplos, torna-se especialmente problemática quando, como no modelo de Gurza Lavalle, Houtzager e Castello, os mecanismos de autorização e de accountability são deixados de lado.

Identificada a presença do "compromisso de representar" nas organizações da sociedade civil, os autores se dedicam a elencar os argumentos que embasam a pretensão de representatividade, tal como aparecem nos discursos das próprias entidades. Os argumentos que ecoam elementos clássicos da democracia representativa - autorização dos representados, afiliação dos representados, identidade com os representados - pouco aparecem. O foco está na prestação de serviços, na proximidade com os representados e, em especial, na capacidade de intermediação. Organizações da sociedade civil se credenciam como representantes na medida em que têm acesso a espaços decisórios que, de outra maneira, estariam vedado a seus representados (Gurza Lavalle, Houtzager e Castello, 2006, p. 52).

\footnotetext{
${ }^{10}$ Burke combina um aspecto de representação virtual (na relação dos eleitores com os cidadãos desprovidos do direito de voto) com outro de representação eleitoral (na relação entre os eleitores e os deputados). Ambos são necessários no seu modelo.
} 
Enquanto as outras justificativas são descartadas como inválidas, esta é considerada adequada ${ }^{11}$. Sua aproximação com a ideia de advocacy é ressaltada e, embora seja anotada a ausência de mecanismos de controle dos pretensos representados sobre seus representantes, o texto prefere ressaltar que a valorização da capacidade de intermediação reflete as transformações na relação que a sociedade civil projeta com o Estado - do antiestatismo predominante no período da ditadura à busca de interlocução que, segundo a quase unanimidade da literatura, marca sua ação no período de redemocratização. "Enquanto o argumento de proximidade permanece fiel à lógica dominante dos atores societários durante o período da ditadura, o argumento de intermediação espelha [...] a conjuntura de inovação institucional dos últimos anos" (Gurza Lavalle, Houtzager e Castello, 2006, p. 58).

Em texto posterior, enfatiza-se o "compromisso subjetivo" com as pessoas que a associação deseja representar 46 (Houtzager e Gurza Lavalle, 2010, p. 4). É uma útil descrição da imagem que estas organizações têm de sua própria ação, mas não serve para fundar o caráter democrático da representação presumida. $\mathrm{Na}$ ausência de mecanismos de controle, o compromisso subjetivo mantém uma relação demasiado assimétrica entre os advocates e seus representados. Ainda mais quando se reconhece que, numa curiosa inversão da visão mais convencional, são os representan-

${ }^{11} \mathrm{O}$ argumento da prestação de serviços aos pretensos representados é considerado incompatível com os "requisitos mínimos da democracia" (Gurza Lavalle, Houtzager e Castello, 2006, p. 57), ao passo que o argumento da proximidade reeditaria os dilemas da democracia direta (Gurza Lavalle, Houtzager e Castello, 2006, p. 58). Considero esta última afirmação pouco sustentada, mas ela foge do foco da discussão aqui proposta. Em textos posteriores, as assimetrias entre as organizações da sociedade civil, que colocam algumas em posição central e relegam outras a posições periféricas, são anotadas, mas não são consideradas graves o suficiente para comprometer o potencial de representação democrática antes identificado (Gurza Lavalle, Castello e Bichir, 2007, 2008; Houzager e Gurza Lavalle, 2010). A fim de não estender em demasia a discussão, no restante deste texto vou me ater basicamente ao artigo original. 
tes que escolhem os representados - "as associações civis podem rejeitar ou aceitar o papel de representantes de constituencies que elas identificam (e definem)" (Houtzager e Gurza Lavalle, 2010, p. 9).

"Sociedade civil, instituições participativas e representação", de Leonardo Avritzer, se move em terreno semelhante, embora não se furte a criticar a abordagem de Gurza Lavalle, Houtzager e Castello. Ele identifica dois processos simultâneos que o levam a falar numa ampliação da representação: a presença de porta-vozes que tematizam questões nos fóruns formais de deliberação e a escolha de organizações como representantes da sociedade civil em novos espaços deliberativos, como os conselhos. Assim, a representação da sociedade civil é vista como uma "superposição de representações sem autorização e/ou monopólio" (Avritzer, 2007, p. 444). O representante "por afinidade" é um ator que age por conta própria, mas se identifica com outros e fala em nome deles (Avritzer, 2007, p. 447).

O esforço teórico sustenta-se em duas contribuições, a de Urbinati, incorporada de forma bem mais expressa que no texto de Gurza Lavalle, Houtzager e Castello, e a de John Dryzek e Simon Niemeyer (uma versão anterior do que se tornou Dryzek e Niemeyer, 2008; Dryzek, 2010). O mérito principal de Urbinati, na leitura de Avritzer, é localizar a eleição como um momento indispensável, mas não exclusivo, da representação e da relação entre Estado e sociedade civil, integrando-a no contexto amplo do julgamento político (Avritzer, 2007, pp. 452-453) ${ }^{12}$. De Dryzek e Niemeyer, por outro lado, ele retira a ideia de uma "câmara de discursos", paralela ao parlamento, em que as diferentes

\footnotetext{
${ }^{12}$ No entanto, o julgamento eleitoral permanece, na obra de Urbinati, com uma centralidade maior do que a atribuída por Avritzer. Ver, por exemplo, Urbinati, 2010. Ao diferenciar o representante eleito do advocate, ele promove um movimento que é estranho ao pensamento de Urbinati, para quem uma das características do eleito é precisamente atuar como advocate.
} 
posições sobre os temas da agenda pública estariam presentes (representadas) e poderiam expor-se mutuamente a seus argumentos de acordo com a cartilha da democracia deliberativa. A composição desta câmara - isto é, a tarefa de “(a) mapear a constelação de discursos relevantes para uma questão e (b) determinar que indivíduos melhor representam cada discurso" (Dryzek e Niemeyer, 2008, p. 486) - é dada como uma questão que se resolve de forma técnica.

Partindo destas duas reflexões, Avritzer constrói uma tipologia em que o representante pode ser um agente (escolhido por meio eleitoral), um advocate ou um "partícipe" (Avritzer, 2007, p. 456) ${ }^{13}$. O advocate se legitima não pela autorização, mas pela "afinidade ou identificação de um conjunto de indivíduos com a situação vivida por outros indivíduos" (Avritzer, 2007, p. 457). Já o partícipe, nessa tipologia, é a organização da sociedade civil, que assume a função de representante em conselhos ou órgãos similares 48 e se legitima por meio de "uma identidade ou solidariedade parcial exercida anteriormente" (Avritzer, 2007, p. 458). É o representante de um conjunto de organizações e associações, pelo qual fala nestes fóruns.

Temos então, sobrepostas, uma representação de pessoas (agentes), outra de "discursos e ideias" (advocates) e uma terceira de "temas e experiências" (partícipes), em fóruns distintos, mas que se comunicam (Avritzer, 2007, p. 458) ${ }^{14}$. Apesar da maior complexidade do modelo que produz, Avritzer, tanto quanto Gurza Lavalle, Houtzager e Castello,

\footnotetext{
13 Avritzer opta por utilizar "advocacia" e "advogado" em lugar das formas inglesas advocacy e advocate. Seu texto ganha em fluência, mas se perde a distinção entre o advocate e o advogado (lawyer). Escolhi, assim, manter as palavras em inglês. ${ }^{14}$ Advocates e partícipes são, muitas vezes, as mesmas organizações, atuando na esfera pública discursiva informal, num caso, e nos novos espaços deliberativos formais, no outro. No restante deste paper, por economia de linguagem, vou usar advocate e advocacy como termos genéricos, que expandem para agentes da sociedade civil o sentido original proposto por Urbinati e englobam tanto os dois modelos alternativos de Avritzer quanto o de Gurza Lavalle, Houtzager e Castello.
} 
tende a equivaler fala na esfera pública com representação e, no passo seguinte, incorporar o adjetivo "democrático", expressa ou tacitamente, a qualquer forma de fala/representação originada na sociedade civil.

Em relação à representação formalista, nesses modelos faltam tanto mecanismos de autorização quanto de prestação de contas. Em relação à representação descritiva, falta a similaridade com o grupo a ser representado. São problemas dos quais os autores mostram consciência, mas que não julgam suficientes para descartar a aposta nessa nova forma de representação, como mecanismo complementar à representação formal. Julgar as novas formas pelos padrões da representação eleitoral é “operação pouco produtiva”, segundo Gurza Lavalle, Houtzager e Castello (2006, p. 45); mais ainda, acusá-las pela ausência de autorização e accountability "cancela em vez de [...] adentrar" o problema (Gurza Lavalle, Houtzager e Castello, 2006, p. 46). Já Avritzer advoga pela "redução da preocupação com legitimidade dessas novas formas de representação", sendo a questão de fato o modo pelo qual elas se sobrepõem, com autorização e representação virtual ocupando os mesmo espaços e falando em nome dos mesmos grupos (Avritzer, 2007, p. 459). Em todos os casos, há um parti pris favorável aos novos modelos de representação, que seriam promotores de uma saudável ampliação da presença da sociedade civil, sendo necessário anular os elementos presentes na teoria tradicional da representação que provocariam uma avaliação crítica de tais formas representativas.

Não há como negar que estes intermediários - organizações da sociedade civil, organizações não governamentais - atuam como representantes, mas a questão é saber se essa forma de representação é democrática. Embora, muitas vezes, os advocates desempenhem papéis que contribuem para o bom funcionamento da democracia, incluindo temas e promovendo a defesa de interesses que, de outra maneira, estariam ausentes, uma série de fatores conduz à conclusão de 
que a resposta à questão é negativa. Nessa discussão, não é possível elidir o problema da legitimidade - e os problemas a ele associados, da autonomia dos representados e da formação das preferências políticas.

Antes de mais nada, cabe observar que autorização e accountability se impõem pela exigência de que existam mecanismos que permitam o controle dos representantes pelos representados. Na sua ausência, ficamos na dependência da "boa vontade" ou da "boa fé" dos representantes, com todos os problemas que isso coloca. Se há alguma coisa que a teoria política, ao longo de sua história, foi capaz de ensinar é que não devemos depender da boa vontade dos governantes. Precisamos de mecanismos institucionais que impeçam a usurpação do poder - daí a ideia de checks and balances, de mecanismos de controle, de desconcentração do poder ${ }^{15}$.

Representantes escolhidos por sorteio (Miguel, 2000) não cumprem estes requisitos - não recebem autorização 50 dos representados, nem são accountable. Tais problemas seriam remediados com a similaridade entre representantes e representados, que a seleção aleatória garante, e sobretudo com o funcionamento do "princípio da rotação" (Manin, 1997), segundo o qual governantes e governados se alternam nessas posições. Os advocates, no entanto, são caracterizados

\footnotetext{
15 Uma posição diferenciada é a de Pierre Rosanvallon, que em sua obra recente tem discutido a crescente desconfiança em relação aos representantes escolhidos por meio eleitoral. Emergem, assim, instituições "destinadas a compensar a erosão da confiança por uma organização da desconfiança” (Rosanvallon, 2006, p. 12; ênfase suprimida). São organismos judiciários ou parajudiciários, públicos ou privados, observatórios, watchdogs etc., voltados à supervisão e contestação do exercício do poder, que ele chama de "contrademocráticos". Sua legitimidade não estaria baseada em autorização e responsividade, mas em imparcialidade, reflexividade ou proximidade (Rosanvallon, 2008). Mas ele observa expressamente que os movimentos contrademocráticos não têm funções representativas (Rosanvallon, 2006, p. 71). As reflexões de Rosanvallon abrem toda uma série de novos desafios, que não têm como ser enfrentados nos limites deste artigo. Para um resumo de seu pensamento, ver Silva (2009). Para uma crítica que o coloca, ao lado de Phillip Pettit, como desejoso de uma "democracia apolítica", que substitui o julgamento político comprometido por um ideal de justiça imparcial, ver a própria Urbinati (2010).
} 
por uma marca de distinção (a competência superior) e tendem a ocupar permanentemente tais funções.

Não é necessária uma grande clarividência para identificar os problemas da autorização eleitoral, submetida a formas de manipulação, sensível ao poder econômico e à influência da mídia, quando não à intimidação aberta. Também os mecanismos de accountability cumprem mal suas promessas, dada a pouca capacidade de supervisão dos representantes pelos representados, o fluxo defeituoso de informações ou os compromissos interpostos com interesses alheios aos dos eleitores (Miguel, 2005). Ainda assim, autorização e accountability são os instrumentos que promovem a incerteza quanto ao exercício do poder, que, como dizia Przeworski (1984 [1983]), é a marca da política democrática. Se são insuficientes, como de fato são, nem por isso são descartáveis. Formas de representação que deles prescindem, como porta-vozes autoinstituídos, quase com certeza estarão em pior situação no que se refere a seu caráter democrático.

Além disso, a legitimidade desses intermediários está vinculada à capacidade de agir, de se colocar publicamente. Diversos grupos, organizações ou mesmo indivíduos podem almejar a posição de porta-vozes de determinadas visões políticas ou interesses sociais. Nem todos, porém, têm condições de se colocar na esfera pública de maneira a reivindicar tal posição. São necessários recursos materiais e simbólicos, providos muitas vezes pelo Estado, por fundações privadas, por organismos multilaterais como o Banco Mundial ou por redes transnacionais de advocacy. Se, na ausência de mecanismos de controle e autorização, essas organizações não prestam contas àqueles cujos interesses dizem representar, devem prestar a seus patrocinadores. Uma ampla literatura discute os problemas da accountability das ONGs, observando, em especial, como as ONGs dos países mais pobres são vulneráveis à agenda de suas "irmãs" do Norte (Brown e Fox, 1998; Sorj, 2005). 
A contraface da capacidade de agir é o reconhecimento como interlocutor válido. Alguém, portanto, o provê: alguém reconhece que determinada organização está credenciada a falar em nome de determinados grupos, experiências ou interesses. Não são os pretensos representados, uma vez que os mecanismos de autorização foram descartados. Então é o Estado que vai convocar representantes da sociedade civil para seus espaços de negociação. Ou outros agentes do campo político, que vão escolher seus interlocutores - incluídas, entre estes agentes, aquelas associações que já conquistaram legitimidade para falar. $\mathrm{Ou}$, ainda, os meios de comunicação de massa, que cumprem seu papel de gatekeepers tanto dos discursos considerados relevantes quanto dos porta-vozes legítimos destes discursos (Miguel, 2002; Gomes, 2004). Enfim, há uma legitimação derivada que pode reforçar as hierarquias e o poder já existentes.

Um elemento importante para gerar legitimidade é a 52 capacidade de adaptação aos modos discursivos dominantes. O padrão discursivo é um poderoso mecanismo de exclusão e de conformidade ao campo (Bourdieu, 1979). Campos excluem, conforme visto na seção anterior, e a exigência de uma determinada modulação da fala - em termos de domínio da norma culta, de vocabulário, de sintaxe, de disposição afetiva, mas também, pensando agora em "fala" no seu sentido mais estrito, de prosódia, sotaque ou tom (Bickford, 2006) - é central nesse processo.

Pedro Vermelho, o macaco que aprende a falar no conto "Relatório para uma academia", de Kafka, conta sua história, mas observa que "só posso retraçar com palavras humanas o que então era sentido à maneira de macaco" e tornou-se incapaz de "alcançar a velha verdade do símio" (Kafka, 1990 [1919], p. 60). Sem ter se tornado inteiramente homem, ele é um "ex-macaco". As imposições do campo político são similares, só aceitando como fala aquilo que preenche determinadas expectativas. A presença de Pedro 
Vermelho, por mais que esteja vestido como gente e mantenha modos impecáveis, certamente causa incômodo nos acadêmicos a quem se dirige. Mas sua fala, humanizada, garante uma identificação que é tanto maior quanto mais ele se afasta de seu passado simiesco.

Não se trata - ou não se trata necessariamente - de cooptação ou de oligarquização, no sentido de Michels (1982 [1914]). É um imperativo de eficácia, na medida em que a recusa à adaptação aos padrões exigidos pelo campo implica em marginalização. Esse imperativo coloca os dominados diante de um dilema entre eficácia e autenticidade que os dominantes não precisam enfrentar.

O problema mais grave dos modelos de advocacy está no paternalismo e autoritarismo subjacentes. O liberalismo presume um grau de capacidade de decisão autônoma por parte das pessoas (e, portanto, que a representação deriva, de alguma maneira, da vontade e consentimento dos representados). É uma posição complexa, pois isso não implica negar a existência e a importância de mecanismos de manipulação e de relações de dominação - onde se coloca boa parte da crítica ao liberalismo. Mas a resposta a isso não é postular uma posição superior, e sim incrementar a produção das condições que permitam a formulação de preferências autônomas. Dito de outra forma, eu não posso pretender me colocar democraticamente na condição de representante de um grupo sem estabelecer um diálogo, em primeiro lugar, com aqueles que desejo representar.

Podemos pensar em três situações:

Há grupos que buscam defender os interesses de seres sem condições de expressar-se por conta própria: o meio ambiente, uma espécie animal, o patrimônio cultural etc. A defesa de tais valores é um dos papéis tradicionalmente reconhecidos da sociedade civil. Mas se pode chamar isso de "representação" apenas graças à polissemia da palavra. O Greenpeace, por exemplo, não se coloca como repre- 
sentante (virtual, por afinidade, por advocacy, como quer que se queira) das "pessoas interessadas em preservar o planeta", mas fala em nome de uma causa ou, metaforicamente, do próprio planeta.

Há grupos em que há necessidade de postular que seus integrantes são dotados da capacidade (potencial, ao menos) de estabelecer autonomamente suas preferências e produzir autonomamente seus interesses. A ideia de que esses grupos serão representados por pessoas alheias a eles é, em si, autoritária. Para pegar um exemplo comum a essa literatura: mulheres ocidentais que falariam em nome das mulheres do Oriente Médio. Eu posso defender mudanças radicais na condição de vida das mulheres do Oriente Médio, posso argumentar (razoavelmente) que as condições de submissão em que se encontram as impedem de reivindicar elas próprias essas mudanças, ou mesmo de desejar estas mudanças. Mas isso não faz de mim um representante 54 delas, um porta-voz delas. As ONGs internacionais feministas, como reconhece Avritzer, representam um "discurso sobre os direitos das mulheres em geral”, não as mulheres (Avritzer, 2007, p. 457).

O ponto a ser destacado é que a existência de tais entidades, que verbalizam a defesa desses direitos, não supre a ausência, na esfera pública, de representantes efetivos das mulheres submetidas a opressão. Os advocates promovem uma forma de substituição que faz com que a autoexpressão dos dominados deixe de aparecer como um problema a ser enfrentado. Afinal, seus direitos ou interesses já se fazem ouvir, defendidos por grupos e indivíduos melhor capacitados. Além disso, o que esses advocates apresentam como sendo as demandas de seus representados virtuais não é, necessariamente, aquilo que eles produzem ou produziriam como preferências caso tivessem acesso a espaços em que pudessem gerá-las de forma autônoma. É aqui que as perspectivas sociais, ignoradas por essa literatura, tornam-se relevantes. 
Como observa Sapiro (1981, p. 704), “não é razoável pensar que sistemas políticos representarão grupos antes não representados até que estes grupos desenvolvam um sentimento de seus próprios interesses e apresentem demandas ao sistema”. A substituição gerada pelos mecanismos de advocacy pode obstaculizar este processo, trabalhando contra a autonomia dos grupos.

Por fim - e esta é a terceira situação -, há grupos em situação ambígua, notadamente pessoas que se julga que não possuem a capacidade de falar por si mesmas na esfera pública. Os dois exemplos mais evidentes são crianças ou indivíduos com problemas mentais. Mesmo aí, há necessidade de tomar cuidado com a presunção de que não é problemático falar em nome de outro. Penso no movimento dos meninos e meninas de rua, que busca dar voz a essas crianças, ou no movimento da neurodiversidade, que reivindica que indivíduos considerados "deficientes mentais", sobretudo os autistas, sejam ouvidos em sua própria voz.

Não se trata de uma questão simples. O slogan "por autistas para autistas", do que é chamado por Ortega (2009, p. 71) de "movimento de autoadvocacia do autismo", invoca a ideia de que há uma diferença (a ser preservada) e não uma doença (a ser tratada). Plausível para autistas altamente funcionais, muitas vezes diagnosticados com a síndrome de Asperger (uma versão "branda", sobre a qual não há sequer consenso em se considerar uma forma de autismo), não o é tanto para os casos extremos, quando não há "nem a capacidade cognitiva de falar nem de dizer o que pensam ou sentem, quanto menos de se organizar política e comunitariamente" (Ortega, 2009, p. 75). Para estes (ou, melhor, para seus pais e aqueles que se colocam como zeladores de seu bem-estar), as formas de integração ou normalização, denunciadas pelos defensores da diferença autista, parecem ser o único caminho para a minoração de severas limitações. 
Assim, emergem conflitos sobre quem pode falar em nome dos autistas - ou em nome de quais autistas. As fronteiras da identidade autista não são facilmente definidas (Baker, 2006; Ortega, 2008). Se é razoável pensar que indivíduos incapacitados precisam ser tutelados, por outro lado o impulso para obter uma voz própria é legítimo e deve ser respeitado. O caso do movimento da neurodiversidade expõe as dificuldades próprias de uma situação limite, mas, também, que a possibilidade de falar com a própria voz é um bem que deve ser estimulado a todos os que dele possam usufruir.

\section{Conclusão}

Em suma, da mesma maneira que a qualidade da representação é um indicador da qualidade da democracia enquanto realização da autonomia coletiva, a representação democrática exige que se fomente a autonomia individual, isto é, que 56 as pessoas sejam capazes de produzir seus próprios interesses a partir da reflexão crítica sobre o mundo e do diálogo com seus semelhantes. Formas de representação como advocacy, embora possam trazer benefícios a curto prazo para integrantes de um ou outro grupo social, não estimulam o exercício dessas autonomias.

A ideia de advocacy tende a equivaler interesses e necessidades ou mesmo priorizar estas últimas. Trata-se de uma posição congruente com seu viés paternalista - a ênfase em necessidades, em vez de interesses, "acomoda-se mais facilmente com a decisão por experts, em favor do grupo necessitado" (Phillips, 1995, p. 73). Ressoa os argumentos das defensoras do pensamento maternal, que rejeitam expressamente os interesses "egoístas" em favor de uma política com estofo moral, voltada à satisfação das necessidades (Diamond e Hartsock, 1981). Necessidade, no entanto, remete a uma categoria pré-política. É na construção dos interesses que se pode exercer uma ação autônoma. 
A ideia de autonomia é central porque implica tanto a capacidade de que os indivíduos produzam, coletivamente, seus próprios interesses quanto que renegociem suas identidades e pertencimentos de grupo. "Autonomia" não significa que o self paira acima e além das relações sociais que o constituem. Mas também não é uma ilusão, uma vez que não seríamos mais do que um produto do nosso pertencimento comunitário - o "quem sou eu?" descartando o "que objetivos eu escolho?”, como no relato de Sandel (1982). Autonomia significa que, embora sejamos seres sociais, somos capazes de desenvolver competências que nos permitem avaliar criticamente as tradições e valores que herdamos (Barclay, 2000). Entendida como um bem social, necessário à democracia, estabelece a necessidade de universalização dos recursos materiais, informacionais e cognitivos que permitem seu desenvolvimento.

O ideal de autonomia é tanto individual quanto coletivo. Uma certa ortodoxia de esquerda denuncia as "noções individualistas de autodeterminação e autonomia do indivíduo, tão caras às projeções da direita neoliberal" (Altamira, 2008 [2006], p. 35) - como se uma pretensa emancipação coletiva pudesse prescindir da emancipação individual. A defesa da autonomia individual, entendida como a capacidade de reflexão crítica em relação ao grupo social, nada tem a ver com o individualismo abstrato ou a ideia de que a sociedade não existe, à la Margaret Thatcher. É um valor que necessita de determinadas condições sociais para se constituir e que estabelece um dos indicadores da qualidade da democracia. E que fortalece os compromissos com o coletivo, na medida em que se tornam mais reflexivos, esclarecidos e pactuados.

Ao mesmo tempo, é importante o entendimento de que a representação envolve uma forma de exercício de poder sobre os representados; portanto, a pluralidade social nos espaços de representação não resolve o problema da igual- 
dade política. Mesmo com a realização ideal de uma representação descritiva, em que o corpo de representantes espelhe perfeitamente o conjunto dos representados, há a manutenção da concentração da capacidade de ação política em alguns poucos indivíduos - que espelhariam melhor a população, é verdade, mas continuariam formando uma elite diferenciada. É necessário não esquecer dos problemas da redistribuição do capital político e do aprimoramento dos mecanismos de supervisão dos representados sobre os representantes.

Não se trata de eliminar a discussão sobre perspectivas, mas de centrar a defesa da presença política no entendimento que a exclusão de determinados grupos dos espaços de tomada de decisão é uma forma de injustiça e tanto reflete quanto realimenta um déficit de poder desses grupos. Sem isso, o foco na representação de perspectivas sociais diversas, inspirado por Young, tem contribuído para obs58 curecer a centralidade da disputa de interesses na política, nivelando os três elementos identificados na representação (interesses, opiniões, perspectivas) e desinflando a relação, que é necessário enfatizar, entre as perspectivas sociais e a produção das preferências.

Por outro lado, a opção pela advocacy recoloca os interesses no centro, mas não valoriza os processos de formação autônoma destes interesses. A dimensão de exercício de poder, presente na representação, é deixada em segundo plano; e o papel das perspectivas sociais na produção das preferências e dos interesses é negligenciado. Tais problemas se revelam já nas formulações de Nadia Urbinati e são agravados naquelas leituras que transferem a advocacy para espaços extraparlamentares, retirando de cena os instrumentos institucionais de autorização e accountability. Não se trata de pretender que a representação formal, por meio de eleições, é a única dotada de potencial de legitimidade, mas de entender que mecanismos de autorização e accountability 
devem ser buscados em todas as formas de representação que se queiram democráticas.

A aposta nas virtudes da representação por meio de advocates parecem animadas pelo desejo de contornar o problema da relação entre igualdade e democracia. Com a aparente irrevogabilidade do capitalismo e o refluxo da defesa de uma ordem social mais igualitária, atrelar a possibilidade de uma democracia efetiva à redução das desigualdades parece impor um veredito negativo: não teremos uma democracia melhor do que a que já temos. Cria-se, então, uma solução que elide a questão. Aqueles que possuem menos recursos (materiais, em primeiro lugar, mas também culturais, no sentido do "capital cultural" de Bourdieu) para a participação política encontram porta-vozes que se dispõem a prover suas necessidades e seu bem-estar. É uma falsa solução, que perpetua a exclusão política e não valoriza a conquista da autonomia.

De uma maneira que à primeira vista talvez pareça paradoxal - pois cada lado da moeda se associa a uma tradição intelectual diferente e muitas vezes oposta -, penso que é necessário combinar a atenção às formas de superação das desigualdades políticas, que atendem aos requisitos normativos de um aprofundamento da democracia, com o reconhecimento realista de que "política diz respeito a interesses e poder". Enfim, esse percurso leva ao entendimento de que os problemas da representação não se entendem plenamente a não ser considerando outras dimensões além da tomada de decisões: a dimensão da participação no debate público (que não se esgota nos espaços formais, como o parlamento ou os conselhos, mas se espraia de diferentes formas, por meio, sobretudo, da mídia) e a dimensão da produção dos interesses. E afirma a necessidade de uma teoria da representação que volte a dar centralidade à categoria do "interesse", mas que leve em conta os processos sociais de produção dos interesses. 


\section{Luis Felipe Miguel}

é professor titular do Instituto de Ciência Política da UnB.

\section{Referências Bibliográficas}

ALTAMIRA, C. 2008 [2006]. Os marxismos do novo século. Rio de Janeiro: Civilização Brasileira.

AVRITZER, L. 2007. "Sociedade civil, instituições participativas e representação: da autorização à legitimidade da ação”. Dados, v. 50, n. 3, pp. 443-464.

BAKER, D. L. 2006. "Neurodiversity, neurological disability and the public sector: notes on the autism spectrum". Disability E Society, v. 21, n. 1, pp. 15-29.

BARCLAY, L. 2000. "Autonomy and the social self". In: MACKENZIE, C.; STOLJAR, N. (orgs.), Relational autonomy: feminist perspectives on autonomy, agency, and the social self. Oxford: Oxford University Press.

BICKFORD, S. 1996. The dissonance of democracy: listening, conflict, and citizenship. Ithaca: Cornell University Press.

BOURDIEU, P. 1979. La distinction: critique sociale du jugement. Paris: Minuit.

BROWN, L. D.; FOX, J. A. 1998. “Accountability within transnational coalitions". In: (orgs.). The struggle for accountability: the World Bank, NGOs, and grassroots movements. Cambridge: MIT Press.

BURKE, E. 1984 [1774]. "Discurso a los electores de Bristol". In: Textos políticos. México: Fondo de Cultura Económica.

DIAMOND, I.; HATSOCK, N. 1981. "Beyond interests in politics: a comment on Virginia Sapiro's 'When are interests interesting? The problem of political representation of women”. American Political Science Review, v. 75, n. 3, pp. 717-721.

DRYZEK, J. S. 2000. Deliberative democracy and beyond: liberals, critics, contestations. Oxford: Oxford University Press. (2010). Foundations and frontiers of deliberative governance. Oxford: Oxford University Press.

; NIEMEYER, S. 2008. "Discursive representation". American Political Science Review, v. 102, n. 4, pp. 481-493.

ELSHTAIN, J. B. (1993 [1981]). Public man, private woman: women in social and political thought. Princeton: Princeton University Press.

ELSTER, J. 1990. "Selfishness and altruism”. In: MANSBRIDGE, J. J. (org.). Beyond self-interest. Chicago: The University of Chicago Press.

FARIA, C. F. 2010. "Do ideal ao real: as consequências das mudanças conceituais na teoria da democracia deliberativa”. Paper apresentado no $7^{\circ}$. Encontro da Associação Brasileira de Ciência Política. Recife. 
FRASER, N. 1992. "Rethinking the public sphere: a contribution to the critique of actually existing democracy”. In: CALHOUN, C. (org.). Habermas and the public sphere. Cambridge: MIT Press

GOMES, W. 2004. Transformações da política na era da comunicação de massa. São Paulo: Paulus.

GODIN, R. E. 2000. "Democratic deliberation within". Philosophy and Public Affairs, v. 29, n. 1, pp. 81-109.

2004. "Representing diversity". British Journal of Political Science, v. 34, n. 3, pp. 453-468.

GURZA LAVALLE, A.; CASTELLO, G. 2008. "Sociedade civil, representação e a dupla face da accountability: cidade do México e São Paulo". Caderno CRH, n. 52, pp. 67-86. ; BICHIR, R. M. 2007. "Protagonistas na sociedade civil: redes e centralidades de organizações civis em São Paulo”. Dados, v. 50, n. 3, pp. 465-498. 2008. "Atores periféricos na sociedade civil: redes e centralidades de organizações civis em São Paulo”. Revista Brasileira de Ciências Sociais, n. 68, pp. 73-96.

; HOUTZAGER, P. P.; CASTELLO, G. 2006. "Representação política e organizações civis: novas instâncias de mediação e os desafios da legitimidade”. Revista Brasileira de Ciências Sociais, n. 60, pp. 43-66.

HARTSOCK, N. C. M. 1998 [1983]. "The feminist standpoint: developing the ground for a specifically feminist historical materialism”. In: The feminist standpoint revisited and other essays. Boulder: Westview.

HIRSCHMAN, A. O. 1979 [1977]. As paixões e os interesses: argumentos políticos a favor do capitalismo antes de seu triunfo. Rio de Janeiro: Paz e Terra.

HOUTZAGER, P. P.; GURZA LAVALLE, A. 2010. “'Civil society' claims to political representation in Brazil”. Studies in Comparative International Development, v. 45, n. 1, pp. 1-29.

KNIGHT, J.; JOHNSON, J. 1997. "What sort of political equality does deliberative democracy requires?”. In: BOHMAN, J.; REHG, W, (orgs.). Deliberative democracy: essays on reason and politics. Cambridge: MIT Press.

KAFKA, F. 1990 [1919]. "Relatório a uma academia”. In: Um médico rural. São Paulo: Brasiliense.

LEFORT, C.; GAUCHET, M. 1971. "Sur la démocratie: le politique et l'institution du social". Textures, n. 2-3, pp. 7-78.

MACPHERSON. C. B. (1977 [1976]). A democracia liberal: origens e evolução. Rio de Janeiro: Jorge Zahar.

MANIN, B. 1997. The principles of representative government. Cambridge: Cambridge University Press. 
MARX, K.; ENGELS, F. 2007 [1846]. A ideologia alemã. São Paulo: Boitempo. MENDONÇA, R. F. 2011. "Teoria crítica e deliberação: diálogos instáveis". Paper apresentado no 20․ Encontro Anual da Associação Nacional de Programas de Pós-Graduação em Comunicação. Porto Alegre.

MICHELS, R. 1982 [1914]. Sociologia dos partidos políticos. Brasília: Editora UnB. MIGUEL, L. F. 2000. "Sorteios e representação democrática”. Lua Nova, n. 50, pp. 69-96.

2002. "Os meios de comunicação e a prática política". Lua Nova, n. 55-56, pp. $155-184$.

2003. "Representação política em 3-D: elementos para uma teoria ampliada da representação política”. Revista Brasileira de Ciências Sociais, n. 51, pp. 123-140.

2005. "Impasses da accountability: dilemas e alternativas da representação política”. Revista de Sociologia e Política, n. 25, pp. 165-178 2010. "Perspectivas sociais e dominação simbólica: a presença política das mulheres entre Iris Marion Young e Pierre Bourdieu”. Revista de Sociologia e Política, n. 36, pp. 25-49.

ORTEGA, F. 2008. "O sujeito cerebral e o movimento da neurodiversidade". Mana, v. 14, n. 2, pp. 477-509. 2009. "Deficiência, autismo e neurodiversidade". Ciência Ẽ Saúde Coletiva, v. 14, n. 1, pp. 67-77.

PERUZZOTTI, E.; SMULOVITZ, C. 2002. “Accountability social: la otra cara del control”. In: (orgs.), Controlando la política: ciudadanos y medios en las nuevas democracias latinoamericanas. Buenos Aires: Temas.

PHILLIPS, A. 1995. The politics of presence. Oxford: Oxford University Press. PRZEWORSKI, A. 1984 [1983]. “Ama a incerreza e serás democrático”. Novos Estudos, n. 9, pp. 36-46.

ROSANVALLON, P. 1998. Le peuple introuvable: histoire de la représentation démocratique en France. Paris: Gallimard. Seuil. 2006. La contre-démocratie: la politique à l'âge de la défiance. Paris: 2008. La légitimité démocratique: impartialité, réflexivité, proximité. Paris: Seuil.

RUDDICK, S. 1989. Maternal thinking: toward a politics of peace. Boston: Beacon Press

SANDEL, M. J. 1982. Liberalism and the limits of justice. Cambridge: Cambridge University Press.

SAPIRO, V. 1981. "When are interests interesting? The problem of political representation of women”. American Political/Science Review, v.75, pp. 701-716. 
SHAPIRO, I. 1999. "Enough of deliberation: politics is about interests and power”. In: MACEDO, S. (org.), Deliberative politics: essays on Democracy and disagreement. Oxford: Oxford University Press.

SILVA, R. 2009. "Pierre Rosanvallon e as metamorfoses da legitimidade democrática”. Paper apresentado no XIV Congresso Brasileiro de Sociologia. Rio de Janeiro.

SORJ, B. 2005. Civil societies North-South relations: NGOs and dependency. Rio de Janeiro: The Edelstein Center for Social Research.

SQUIRES, J. 2001. "Representing groups, desconstruting identities". Feminist Theory, v. 2, n. 1, pp. 7-27.

SUNSTEIN, C. R. 1997. Free markets and social justice. Oxford: Oxford University Press.

URBINATI, N. 2000. "Representation as advocacy: a study of democratic deliberation”. Political Theory, v. 28, n. 6, pp. 758-786. 2006. Representative democracy: principles \& genealogy. Chicago: University of Chicago Press. . 2010. "Unpolitical democracy". Political Theory, v. 38, n. 1, pp. 65-92. .; WARREN, M. E. 2008. "The concept of representation in contemporary democratic theory”. Annual Review of Political Science, v. 11 , pp. 387-412.

YOUNG, I. M. 1990a. Justice and the politics of difference. Princeton: Princeton University Press. 1990b. On female body experience: "throwing like a girl" and other essays. Oxford: Oxford University Press. 2000. Inclusion and democracy. Oxford: Oxford University Press. 2001. "Activist challenges to deliberative democracy". Political Theory, v. 29, n. 5, pp. 670-690. 